This paper is part of the Proceedings of the $3^{\text {rd }}$ International Conference on Design,

\title{
Applications of system dynamics modelling for management policy implementation of a water supply system
}

\author{
S. Park \& G. M. Kim \\ Department of Civil Engineering, \\ Pusan National University, South Korea
}

\begin{abstract}
The purpose of this research is to review the existing philosophy for development and management of water supply and sewerage systems and examine management policies to cope with the paradigm shift in water production and usage. To this end, computer simulation models using system dynamics methodology were developed to analyse the effects of implementing investment policies to enhance the customer satisfaction of a water supply system. In this paper a system dynamics computer simulation model was developed for the simulation of the effects of investment on water quality improvements in the upstream region of Nak-Dong River basin from which Busan in South Korea takes raw water. A Water Service Satisfaction Index that can be used to evaluate a consumer's overall level of satisfaction in the water supply service was also developed in this study. Various scenarios for the treatment efficiency of wastewater treatment facilities were examined using the developed system dynamics model in which the developed Water Service Satisfaction Index was incorporated. The developed model can be further expanded to experiment various scenarios for the management of water supply systems.

Keywords: investment policies, computer simulation, management scenarios, system dynamics, water supply system, water supply service.
\end{abstract}

\section{Introduction}

Busan is the second largest city in South Korea with more than 3 million residents located at the southern tip of the Korean peninsula. It has been generally recognized that the pollution in Nak-Dong River from which Busan takes raw 
water is the main cause of the low usage rate of tap water among the citizens in Busan. This also results in the low level of satisfaction for the provided water service.

Three ways may be considered to improve the level of water supply service in Busan:

(1) Increase investments on the existing water supply facilities such as replacement or rehabilitation of deteriorated pipes;

(2) Develop new alternate water source which can provide high quality water to the consumers, and

(3) Improve the quality of water upstream of Nak-Dong River so that the water quality of Nak-Dong River is improved.

In this study the third one among the three alternatives above was examined by developing a system dynamics computer simulation model based on the system dynamics model by Park et al. [1]. The model was developed to evaluate the effects of investment on water quality improvements in the upstream region of Nak-Dong River basin from which Busan takes raw water. In addition, a Water Service Satisfaction Index was developed that can be used to evaluate a consumer's overall level of satisfaction in the water supply service.

The System Dynamics Methodology developed by Forrester [2] is a simulation methodology based on systems theory. It deals with the interpretation of the dynamic nature of systems in which information and material feedback are present. The methodology can facilitate understanding of a system by extracting structures essential to its working mechanisms, and, based on an analysis of feedback structures inherent to the system, lead to development of efficient management strategies.

Computer simulation models that are developed based on a system dynamics methodology are composed of four basic components: stocks, flows, converters, and interrelations among them, which are graphically represented as arrows and mathematically modelled as the finite difference equations. The value of each component is calculated at each delta time $(D T)$ for a specified simulation time period defined in a model, starting at the initial values of the stocks, and based on the functional relations among components. Computer simulation experiments using a system dynamics methodology are realized using object-oriented modelling software such as Vensim, Powersim Studio, AnyLogic, STELLA, etc. Figure 1 provides an example of a system dynamics computer model that shows a causal feedback loop diagram of a reservoir system with outflows and the corresponding stock-and-flow representation of the model using STELLA.

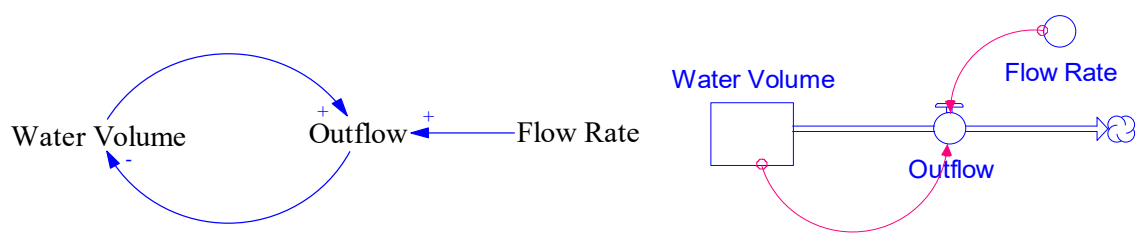

Figure 1: A causal diagram and the corresponding stock-and-flow model using STELLA. 


\section{The System Dynamics Model}

Figures 2-7 show the stock and flow diagrams of the six sub-models of constructed using STELLA.: Water Supply, Pipe Maintenance, Water Supply Business, Water Service Satisfaction Index, Alternate Water Source and Upstream Region submodels. The Water Supply Sub-model modelled the changes in 'supply ratio' due to population changes and pipeline extension, as well as the long-term changes in 'total (volume of) water produced (per year) $\left[\mathrm{m}^{3} / \mathrm{yr}\right]$ ', which are affected by the changes in 'leakage' due to pipe deterioration. In the Pipe Maintenance Sub-model, the conditions of pipes were defined as 'deteriorated pipes [km]', 'nondeteriorated pipes $[\mathrm{km}]$ ' and 'disposed-of pipes $[\mathrm{km}]$ '. In the Water Supply

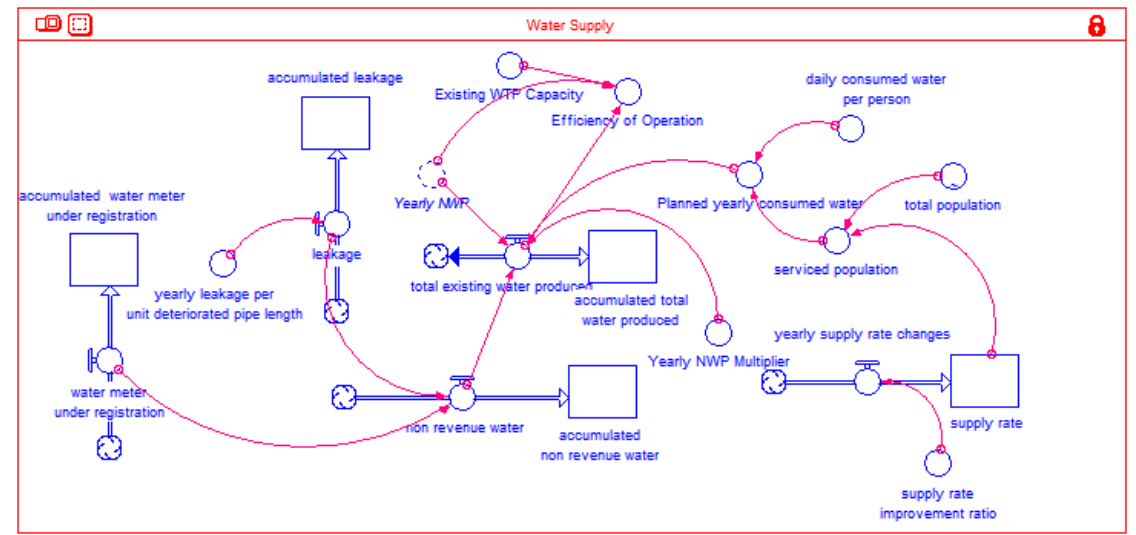

Figure 2: Water Supply Sub-model.

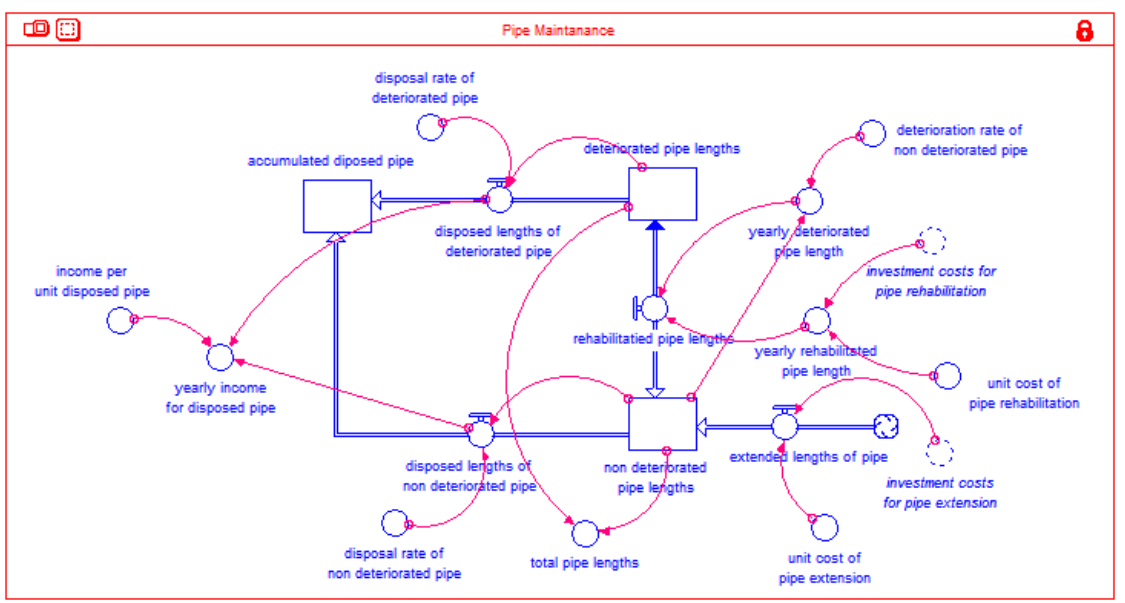

Figure 3: Pipe Maintenance Sub-model. 


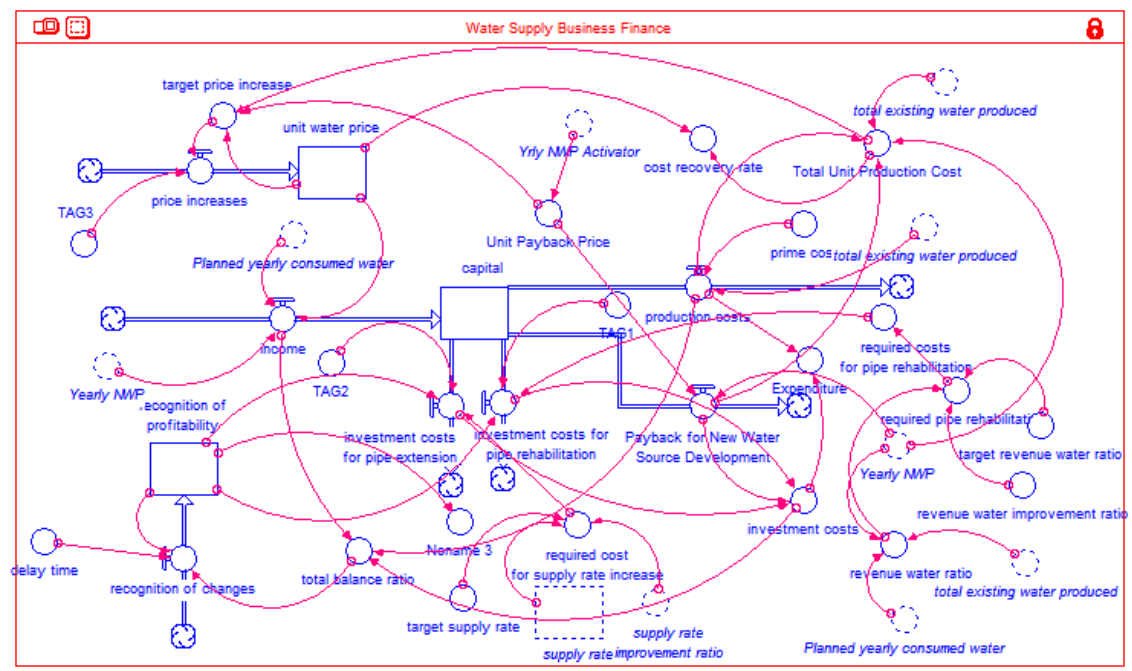

Figure 4: Water Supply Business Finance Sub-model.

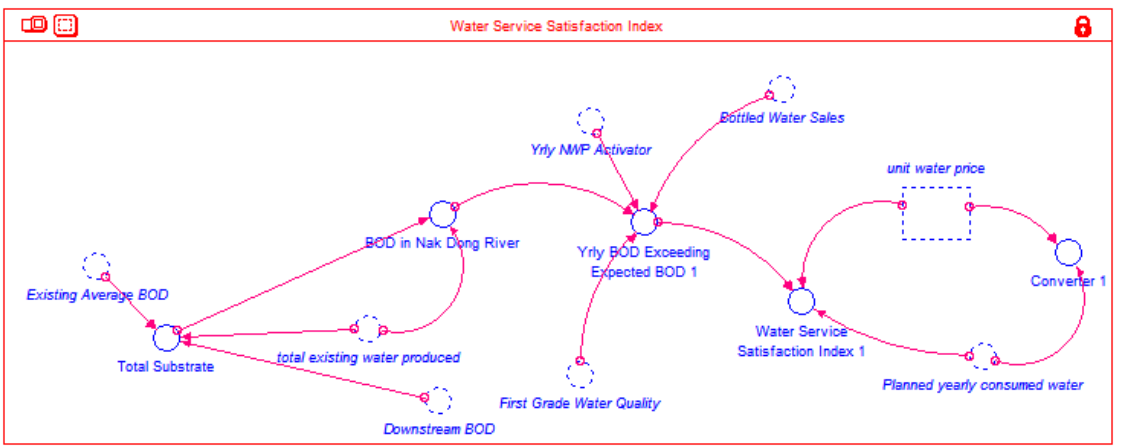

Figure 5: Water Service Satisfaction Index sub-model.

Business Finance Sub-model, the indicators able to represent the financial status of a water supply system were modelled, and included 'income', 'production costs', 'investment costs for pipe rehabilitation' and 'investment costs for pipe extension'. The Upstream Region sub-model modelled the quantity of pollutants in upstream in terms of biochemical oxygen demand (BOD) [mg.L]. The BOD in the upstream watershed was modelled to be changed based on the generated and treated quantity of BOD in the upstream region. The simulation period used for the model was from year 1999 to 2038.

Tables 1-4 show the initial values of the stock variables and the values or trend equations of the exogenous variables used for the SD model. The values and equations in Tables 1-4 were obtained from various reports on the water supply, wastewater treatment and environmental statistics published by the government and agencies of South Korea. Detailed methods used to obtain 
the initial values and functions of times for the stock variables and converters are explained in Park et al. [3].

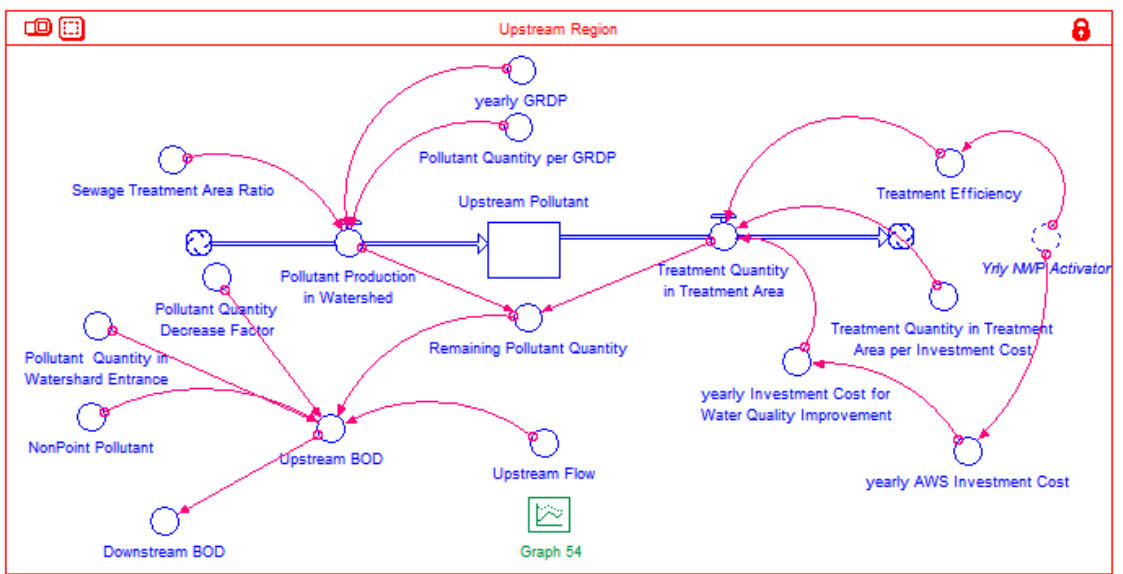

Figure 6: Upstream Region Sub-model.

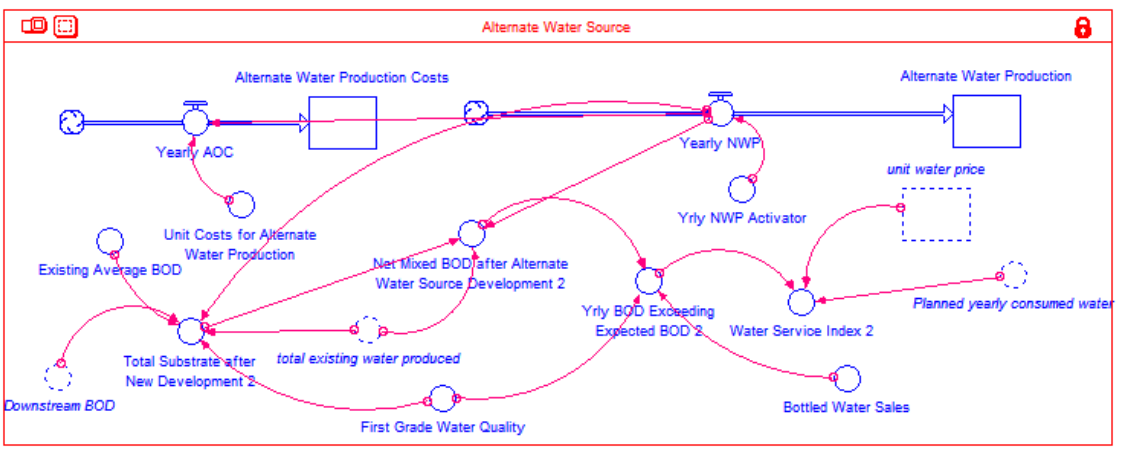

Figure 7: Alternate Water Source Sub-model.

Table 1: The stock and exogenous variables of the Water Supply Sub-model.

\begin{tabular}{|c|c|c|c|}
\hline Variable type & Variable name & Initial value or equation & Unit \\
\hline \multirow{4}{*}{$\begin{array}{l}\text { Exogenous } \\
\text { variables }\end{array}$} & $\begin{array}{l}\text { Yearly leakage per unit } \\
\text { deteriorated pipe length }\end{array}$ & $27985 \cdot \exp (-0.10 \cdot$ time $)$ & $\left(\mathrm{m}^{3} / \mathrm{yr}\right) / \mathrm{km}$ \\
\hline & $\begin{array}{l}\text { Daily Consumed Water Per } \\
\text { Person }\end{array}$ & 254.96 & \\
\hline & Yearly NWP Multiplier & 1 & - \\
\hline & $\begin{array}{c}\text { Supply Rate Improvement } \\
\text { Ratio } \\
\end{array}$ & $1.75 \mathrm{E}-7 \cdot \ln ($ time $)+6.222 \mathrm{E}-6$ & $(1 / \mathrm{yr}) / \mathrm{km}$ \\
\hline \multirow{3}{*}{ Stock } & Supply rate & 0.981 & - \\
\hline & Accumulated leakage & $81,378,000$ & $\mathrm{~m}^{3}$ \\
\hline & $\begin{array}{l}\text { Accumulated water meter } \\
\text { under registration }\end{array}$ & $75,982,000$ & $\mathrm{~m}^{3}$ \\
\hline
\end{tabular}


Table 2: The stock and exogenous variables of the Pipe Maintenance Submodel.

\begin{tabular}{|c|c|c|c|}
\hline Variable type & Variable name & Initial value or equation & unit \\
\hline \multirow{7}{*}{$\begin{array}{c}\text { Excome per } \\
\text { variables } \\
\text { unit disposed pipe }\end{array}$} & 200 & $1,000 \mathrm{Won} / \mathrm{km}$ \\
\cline { 2 - 4 } & $\begin{array}{c}\text { disposal rate of deteriorated } \\
\text { pipe }\end{array}$ & If time $<=5$ then 0.03 else 0.01 & $1 /$ year \\
\cline { 2 - 4 } & $\begin{array}{c}\text { deterioration rate of } \\
\text { non deteriorated pipe }\end{array}$ & If time $<=5$ then 0.075 else 0.03 & $1 /$ year \\
\cline { 2 - 4 } & $\begin{array}{c}\text { unit cost of } \\
\text { pipe rehabilitation }\end{array}$ & $53548 \cdot$ time $\wedge 0.524$ & 1,000 Won $/ \mathrm{km}$ \\
\cline { 2 - 4 } & $\begin{array}{c}\text { unit cost of } \\
\text { pipe extension }\end{array}$ & $8176.47 \cdot \ln ($ time $)+113965.34$ & 1,000 Won $/ \mathrm{km}$ \\
\cline { 2 - 4 } & $\begin{array}{c}\text { disposal rate of } \\
\text { non deteriorated pipe }\end{array}$ & $\begin{array}{c}\text { If time }<=5 \text { then } 0.07 \text { else if } \\
\text { time }>13 \text { then } 0.010 \text { else } 0.004\end{array}$ & $1 /$ year \\
\hline \multirow{3}{*}{ Stock } & Non-deteriorated lengths & $5,504.2$ & $\mathrm{Km}$ \\
\cline { 2 - 4 } & Deteriorated lengths & $2,963.8$ & $\mathrm{Km}$ \\
\cline { 2 - 4 } & Accumulated disposed pipe & 84.68 & $\mathrm{~km}$ \\
\hline
\end{tabular}

In this study an index that can be used to evaluate a consumer's overall level of satisfaction in the water supply service was developed. Eq. (1) represents the index developed in this study.

$$
\text { Water Service Satisfaction Index }=\frac{\text { Yearly BOD Exceeding Expected BOD }}{\text { Unit Water Price } \times \text { Yearly Water Consumption }}
$$

The units of the Water Service Satisfaction Index, Yearly BOD Exceeding Expected BOD, Unit Water Price and Yearly Water Consumption are $\mathrm{mg} / 1,000 \mathrm{Won}, \mathrm{mg} / \mathrm{yr}, 1,000 \mathrm{Won} / \mathrm{m}^{3}$ and $\mathrm{m}^{3} / \mathrm{yr}$, respectively. The Water Service Satisfaction Index is modelled in Figure 5.

Table 3: The stock and exogenous variables of the Water Supply Business Finance Sub-model.

\begin{tabular}{|c|c|c|c|}
\hline Variable type & Variable name & Initial value or equation & unit \\
\hline \multirow{8}{*}{$\begin{array}{l}\text { Exogenous } \\
\text { variables }\end{array}$} & TAG 1 & 10 & year \\
\hline & TAG 2 & 4.5 & year \\
\hline & TAG 3 & 17 & year \\
\hline & delay time & 1 & year \\
\hline & target supply rate & 1 & - \\
\hline & prime cost & $0.018 \cdot$ time +0.603 & 1,000 won $/ \mathrm{m}^{3}$ \\
\hline & target revenue water ratio & 1 & - \\
\hline & $\begin{array}{c}\text { revenue water improvement } \\
\text { ratio }\end{array}$ & $5,451.66$ & $1,000 \mathrm{won} / \mathrm{m}^{3}$ \\
\hline \multirow{3}{*}{ Stock } & Capital & $212,918,197$ & 1,000 won \\
\hline & recognition of profitability & 0.4 & - \\
\hline & unit water price & 0.4754 & 1,000 won $/ \mathrm{m}^{3}$ \\
\hline
\end{tabular}


Table 4: The stock and exogenous variables of the Alternate Water Source Sub-model.

\begin{tabular}{|c|c|c|c|}
\hline Variable type & Variable name & Initial value or equation & unit \\
\hline \multirow{4}{*}{$\begin{array}{c}\text { Exogenous } \\
\text { variables }\end{array}$} & Existing Average BOD & $-450.6 \cdot \ln ($ time $)+4378$ & $\mathrm{Mg} / \mathrm{m}^{3}$ \\
\cline { 2 - 4 } & $\begin{array}{c}\text { Unit Costs for Alternate Water } \\
\text { Production }\end{array}$ & $\begin{array}{c}\text { if time }>=20 \text { then } 0.018 \cdot(\text { time- } \\
20)+0.0512 \text { else } 0\end{array}$ & $1,000 \mathrm{won} / \mathrm{m}^{3}$ \\
\cline { 2 - 4 } & Yrly NWP Activator & 0 & - \\
\cline { 2 - 4 } & Bottled Water Sales & $\begin{array}{c}\text { if time }<=5 \text { then }-6077.2 \cdot \text { time } \\
+53225 \cdot \operatorname{time}+54555 \text { else } \\
101425 \cdot \mathrm{LN}(\text { time })-5971\end{array}$ & $\mathrm{~m}^{3} / \mathrm{yr}$ \\
\cline { 2 - 4 } & Alternate Water Average BOD & 1,000 & $\mathrm{mg} / \mathrm{m}^{3}$ \\
\hline \multirow{3}{*}{ Stock } & $\begin{array}{c}\text { Alternate Water Production } \\
\text { Costs }\end{array}$ & 0 & $1,000 \mathrm{won}$ \\
\cline { 2 - 4 } & Alternate Water Production & 0 & $\mathrm{~m}^{3}$ \\
\hline
\end{tabular}

The 'Unit Water Price' in Eq. (1) is calculated by the SD model based on the required price increases to reduce the difference between the costs of water production and the current value of unit water price. 'Yearly BOD Exceeding Expected BOD' is calculated using Eq. (2).

Yearly BOD Exceeding Expected BOD = Bottled Water Sales $\times$

(BOD in Nak Dong River - First Grade Water Quality)

'Yearly BOD Exceeding Expected BOD' represents the artificial amount of BOD consumed by the customers due to the BOD in Nak-Dong River in excess of the customer's expected BOD of the river (First Grade Water Quality) which was assumed to be $1,000 \mathrm{mg} / \mathrm{m}^{3}$. 'BOD in Nak Dong River' $\left[\mathrm{mg} / \mathrm{m}^{3}\right]$ is changed according to the water quality in the upstream region. 'Bottled Water Sales' $\left[\mathrm{m}^{3} / \mathrm{yr}\right]$ is the amount of bottled water sold in Busan which was estimated based on the data from the Ministry of Environment as in Figure 8.

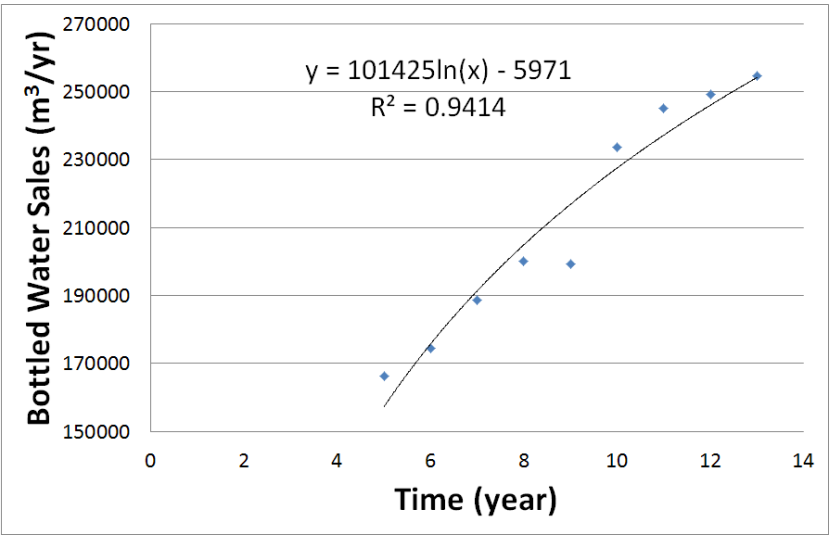

Figure 8: Bottled water sales in Busan during 2003-2011. 
Table 5: The stock and exogenous variables of the Upstream Region Submodel.

\begin{tabular}{|c|c|c|c|}
\hline $\begin{array}{l}\text { Variable } \\
\text { type }\end{array}$ & Variable name & Initial value or equation & unit \\
\hline \multirow{8}{*}{$\begin{array}{l}\text { Exogenous } \\
\text { variables }\end{array}$} & $\begin{array}{l}\text { Sewage Treatment Area } \\
\text { Ratio }\end{array}$ & $\begin{array}{c}\text { if time }<33 \text { then }- \\
0.092 \cdot \ln (\text { time })+1.3187 \text { else } 1 \\
\end{array}$ & - \\
\hline & yearly GRDP & $93753 \cdot$ time $+5 \mathrm{E}+06$ & million/yr \\
\hline & Pollutant Quantity per GRDP & $7,833,200$ & $\mathrm{mg} /$ million \\
\hline & $\begin{array}{c}\text { Pollutant Quantity Decrease } \\
\text { Factor } \\
\end{array}$ & 0.92 & - \\
\hline & $\begin{array}{l}\text { Pollutant Quantity in } \\
\text { Watershed Entrance }\end{array}$ & $9,842,300,000,000$ & $\mathrm{mg}$ \\
\hline & NonPoint Pollutant & $16,844,100,000,000$ & $\mathrm{mg}$ \\
\hline & $\begin{array}{l}\text { Treatment Quantity in } \\
\text { Treatment Area per } \\
\text { Investment Cost }\end{array}$ & $50,715,000$ & $\mathrm{mg} / \mathrm{million}$ \\
\hline & Upstream Flow & $15,474,000,000$ & $\mathrm{~m}^{3}$ \\
\hline Stock & Upstream Pollutant & $627,352,850,820$ & $\mathrm{mg}$ \\
\hline
\end{tabular}

\section{Results and conclusions}

Figure 9 shows the changes in the Water Service Satisfaction Index for the case that the wastewater treatment efficiency in the upstream region is improved. The graph ' 1 ' in Figure 9 represents the simulation results of the Water Service Satisfaction Index when the treatment efficiency is $65 \%$ which is the case for "no improvement' in the treatment efficiency. The graphs ' 2 ', ' 3 ' and ' 4 ' represent the case when the treatment efficiency was improved to $75 \%, 85 \%$ and $95 \%$, respectively. As the graphs '2', ' 3 ' and '4' show, the Water Service Satisfaction Index was predicted to be improved in the order of the increase in the treatment efficiency compared to the case of 'no improvement'. The decrease of the Water

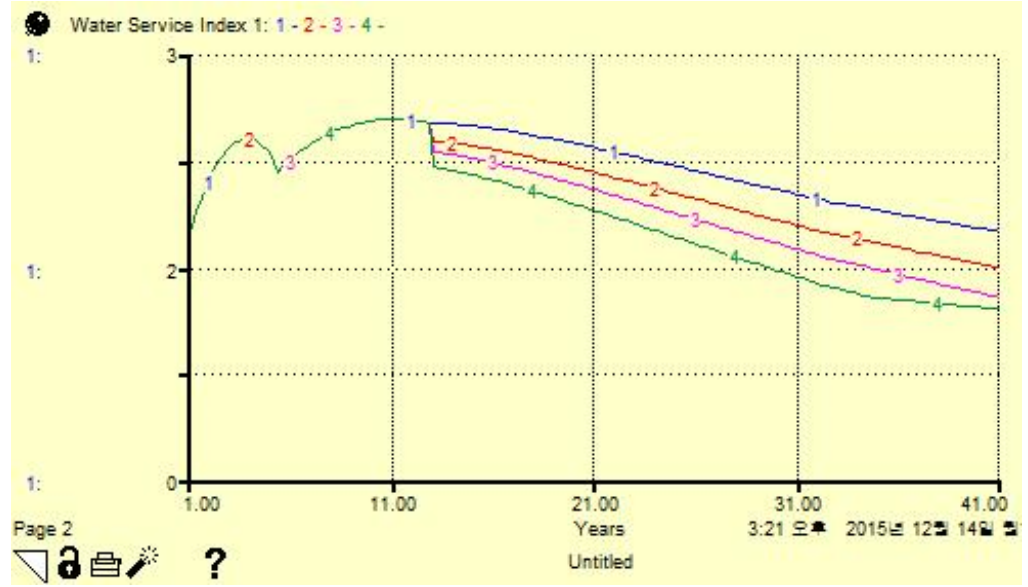

Figure 9: Simulation results of the Water Service Satisfaction Index. 


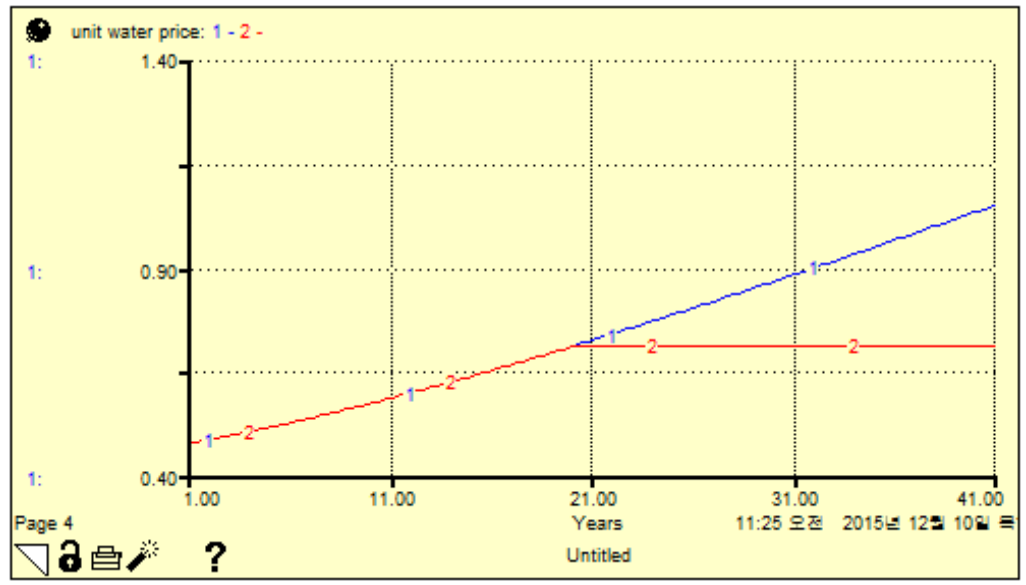

Figure 10: Simulation results of the Unit Water Price.

Service Satisfaction Index is mainly due to the decrease of the BOD in the raw water caused by the improved treatment efficiency. The Water Service Satisfaction Index is designed to be decreased when the level of service improves.

The declining trend of the Water Service Satisfaction Index for the treatment efficiency of $95 \%$ gets lessened due to the high treatment efficiency and the increasing unit water price which is shown in Figure 10.

The developed model was able to quantify the benefits of investing on the wastewater treatment efficiency in the upstream region of Nak-Dong River basin in terms of the developed Water Service Satisfaction Index.

However, investing in the upstream region of Nak-Dong River basin will also have a positive impact on the overall environmental condition along the course of flow of Nak-Dong River. To evaluate the whole effects of improvements of wastewater treatment efficiency in upstream region of a river basin the Water Service Satisfaction Index needs to be evaluated need to be evaluated more comprehensively by incorporating the benefits on the residents along the river basin. The System Dynamics model developed in this study needs to be further modified and expanded to incorporate the broader effects of the investments on the upstream region.

\section{Acknowledgements}

This work was supported by the Korean Ministry of Environment as "Projects for Public Welfare Technology Development (2014000700001)”. 


\section{References}

[1] Park, S., Sahleh, V., and Jung, S.Y., A System Dynamics Computer Model to Assess the Effects of Developing an Alternate Water Source on the Water Supply Systems Management, 13th Computer Control for Water Industry Conference, CCWI 2015, Procedia Engineering, 119, pp. 753-760, 2015.

[2] Forrester, J. W., Industrial dynamics, Waltham, MA: Pegasus Communications, 1961.

[3] Park, S., Jeon, D. H., Jung, S.Y., Developing efficient management strategies for a water supply system using system dynamics modelling. Civil Engineering and Environmental Systems, 31(3), pp. 189-208, 2014. 